\title{
Is There Any Difference between Intermediate-Acting and Long-Acting Calcium Antagonists in Diurnal Blood Pressure and Autonomic Nervous Activity in Hypertensive Coronary Artery Disease Patients?
}

\author{
Satoshi HOSHIDE, Kazuomi KARIO, Takeshi MITSUHASHI, \\ Uichi IKEDA, and Kazuyuki SHIMADA
}

\begin{abstract}
Recently, there have been some reports indicating that calcium antagonists induce a reflex increase in sympathetic activity, triggering cardiac events, especially in coronary artery disease (CAD) patients. In this study, we assessed heart rate (HR) variability (HRV) using power spectral analysis of the 24-h RR interval in 25 hypertensive outpatients with CAD treated with nifedipine. We compared blood pressure (BP), HR, and HRV variation in the same patients substituting benidipine (long-acting) for nifedipine (intermediateacting). There were no significant differences in 24-h, daytime, nighttime, and morning BP between the nifedipine phase and the benidipine phase. HRV parameters (LF: low frequency power, HF: high frequency power, LF/HF ratio) also showed no significant differences in 24-h, daytime, nighttime, and morning LF, HF, and LF/HF ratio between the nifedipine phase and the benidipine phase. Blood pressure, HR, and HRV parameters, except the LF component from 2 to $4 \mathrm{~h}$ after nifedipine administration (the most effective duration), showed no differences compared to before administration. The LF component after the nifedipine administration was lower than before administration. In conclusion, in hypertensive patients with CAD, whose BP levels were well-controlled by twice-daily use of intermediate-acting nifedipine, switching from nifedipine to a long-acting calcium antagonist, benidipine, maintained well-controlled BP levels to a similar degree, but it may not have additional benefit in sympatho-vagal balance.
\end{abstract}

(Hypertens Res 2000; 23: 7-14)

Key Words: nifedipine, benidipine, ambulatory blood pressure monitoring, heart rate variability, coronary artery disease

\section{Introduction}

Recent studies suggest that short-acting calcium antagonists increase coronary artery morbidity and mortality, and non-cardiovascular complications $(1,2)$. In the Sixth Report of the Joint National Committee (JNC VI) of USA (3), immediate-release nifedipine was shown to precipitate ischemic events and, in large doses, may increase coronary mortality in patients who have had myocardial infarction. The report stated that this agent should be used only with great caution, if at all, and long-acting calcium antagonists were recommended. The reflex increase in sympathetic activity induced by short-acting calcium antagonists provoked the observed proischemic, negative inotropic, and arrhythmogenic effects, triggering cardiac events and death, especially in coronary artery disease (CAD) patients (4). Thus the long-acting versions may be

From the Department of Cardiology, Jichi Medical School, Tochigi, Japan.

Address for Reprints: Kazuomi Kario, M.D., Ph.D., Department of Cardiology, Jichi Medical School, 3311-1, Yakushiji, Minamikawachi, Kawachi, Tochigi 329-0498, Japan.

Received May 15, 1999; Accepted in revised form September 27, 1999. 
Table 1. Clinical Characteristics of the Study Group $(n=$ 25)

\begin{tabular}{lll}
\hline Age, $\mathrm{yr}$ & 62.9 & $(6.3)$ \\
Male & 20 & $(80 \%)$ \\
Body mass index, $\mathrm{kg} / \mathrm{m}^{2}$ & 29.4 & $(3.7)$ \\
Smoking & 10 & $(40 \%)$ \\
Dislipidemia & 9 & $(36 \%)$ \\
$\quad$ Treated & 6 & $(24 \%)$ \\
Myocardial infarction & 7 & $(28 \%)$ \\
\hline
\end{tabular}

Mean (SD). The numbers (percentages) shown are mean, except age and body mass index.

a safe alternative, avoiding this sympathetic activation (5). Both short-acting and intermediate-acting calcium antagonists have trough-peak blood pressure (BP) response ratios of less than the $50 \%$ recommended by the U.S. Food and Drug Administration (FDA), while that of long-acting agents is over $60 \%$ (6).

Recently, Holter ECG has been used for the monitoring of spontaneous heart rate variability (HRV) to assess diurnal sympathetic and parasympathetic cardiac tone (7, 8 ). Also, instead of the short-acting or intermediateacting forms, long-acting calcium antagonist is being used more commonly. We studied the benefit of switching to the long-acting form (benidipine) in hypertensive patients with $\mathrm{CAD}$, in whom $\mathrm{BP}$ has been well-controlled by intermediate-acting calcium antagonist (nifedipine) for a long period. We measured diurnal BP changes and cardiac autonomic activity assessed by HRV.

\section{Patients and Methods}

\section{Patients}

We studied 25 hypertensive outpatients with CAD, who had been treated with nifedipine for at least 3 mo before entering this study. They all had had chest pain and had been diagnosed by exercise stress test (both exercise electrocardiography and stress myocardial perfusion imaging with ${ }^{201}$ thallium). Coronary arteriography was performed in 22 patients. The clinical characteristics of the patients who entered the study are shown in Table 1 . All of the patients were ambulatory. Their office BP was defined as the average for each patient on 3 occasions. We excluded outpatients with diabetes mellitus, renal failure, or hepatic damage (glycohemoglobin $>6.0 \%$, serum creatinine level $>130 \mathrm{mmol} / \mathrm{l}$, and asparate aminotransferase or alanine aminotransferase level $>40$ IU/L) from this study.

\section{Design}

All patients had been under monotherapy using $10 \mathrm{mg}$ or
$20 \mathrm{mg}$ nifedipine twice a day after breakfast and dinner. We substituted $4 \mathrm{mg}$ benidipine for $20 \mathrm{mg}$ nifedipine and $8 \mathrm{mg}$ benidipine for $40 \mathrm{mg}$ nifedipine. Noninvasive ambulatory monitoring of BP and RR interval was carried out throughout the period of nifedipine administration and at least $4 \mathrm{wk}$ after benidipine administration. This study was approved by the ethical committee of the Department of Cardiology at Jichi Medical School, and informed consent was obtained from all of the participants.

\section{Ambulatory BP Monitoring and HRV Assessment}

Noninvasive ambulatory monitoring of BP and RR intervals was carried out on a weekday with an automatic ambulatory BP monitor (TM-2420, A\&D Co.,Inc., Tokyo, Japan), which was equipped with ambulatory 24-h ECG monitoring. The accuracy of this device was previously validated (9). The ambulatory BP data used on that day were obtained by the oscillometric method. Both $\mathrm{BP}$ and heart rate (HR) were measured every $30 \mathrm{~min}$ for $24 \mathrm{~h}$.

The RR interval data were analyzed using the fastFourier transform method. Power spectral densities of rhythmic oscillations over a frequency range of $0.4 \mathrm{~Hz}$ or less were obtained during all beats every $5 \mathrm{~min}$ to analyze the low-frequency power (LF: 0.04 to $0.15 \mathrm{~Hz}$ ) as an index of both sympathetic nervous and parasympathetic nervous system activity, the high-frequency power (HF: 0.15 to $0.40 \mathrm{~Hz}$ ) as an index of parasympathetic nervous system activity $(10,11)$, and the $\mathrm{LF} / \mathrm{HF}$ ratio as an indirect index of sympathetic nervous activity $(10,11)$.

Each subject recorded an activities journal in which he or she noted information about the exact times of going to bed and waking up, to determine the daytime and nighttime periods. The nighttime values for HRV parameters (LF, HF, and the $\mathrm{LF} / \mathrm{HF}$ ratio) and $\mathrm{BP}$ parameters were calculated as the mean value from the time the patient went to bed until the time of awakening, and the daytime values were calculated as the mean values during the remaining period. The morning period was defined as the average 2-h period after arising from bed, as stated in each patient's diary. No participants documented disturbed sleep (frequent awakening during sleep) in the present study.

\section{Statistics}

Unless otherwise stated, data are expressed as mean \pm SE. The distribution of $\mathrm{LF}, \mathrm{HF}$, and $\mathrm{LF} / \mathrm{HF}$ ratios was highly skewed; these data were normalized after transformation into natural logarithms for parametric analysis. Two-tailed paired $t$-test was used for comparison of the $\mathrm{BP}, \mathrm{HR}$, and HRV parameters during nifedipine therapy and during benidipine therapy. Differences of $p<0.05$ were considered significant. 

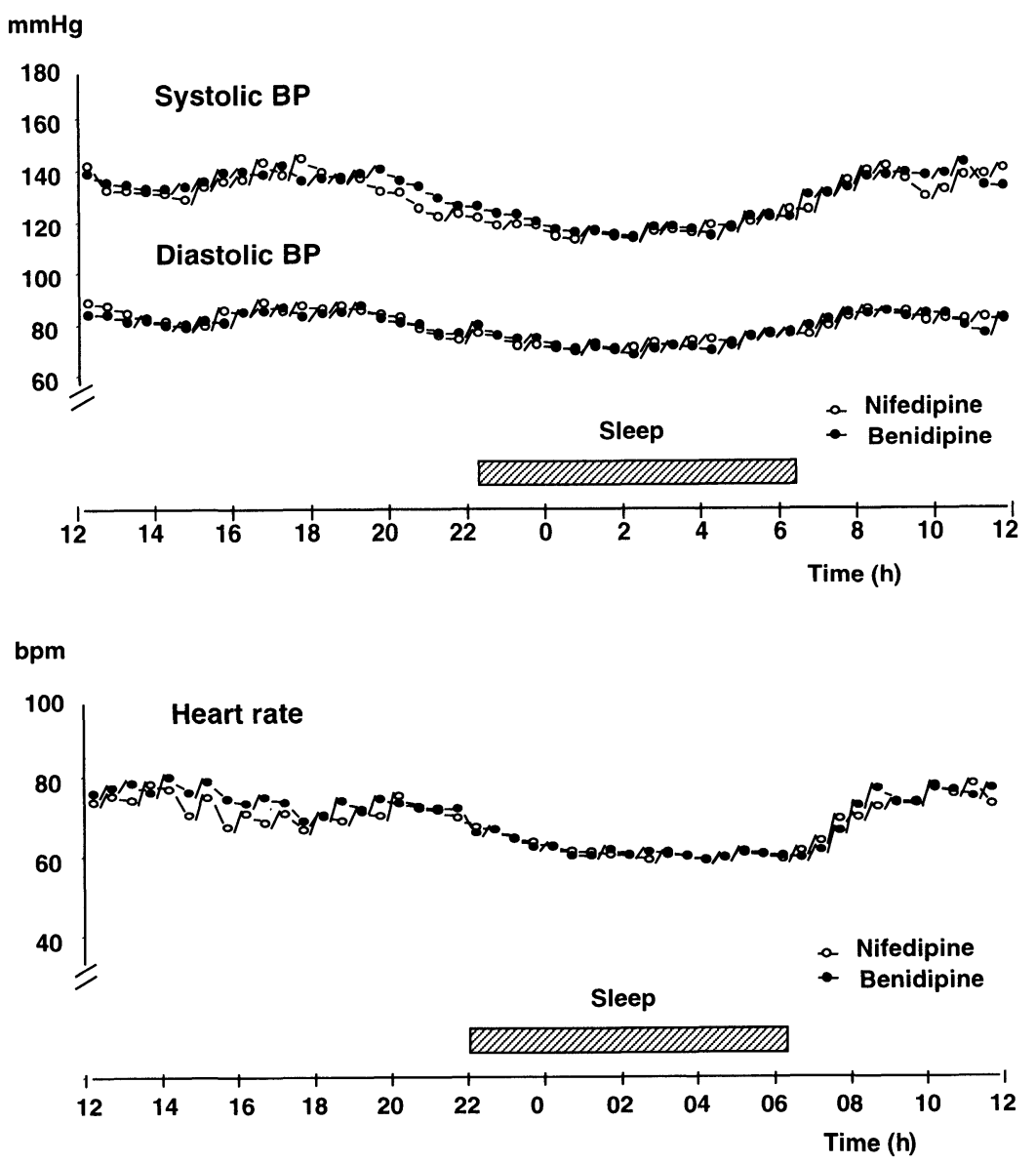

Fig. 1. Twenty-four-hour ambulatory recordings of mean systolic and diastolic blood pressure (BP) and heart rate during nifedipine and benidipine treatment in 25 hypertensive patients with coronary artery disease.

\section{Results}

\section{Diurnal Blood Pressure Variation and Heart Rate}

Figure 1 shows the diurnal $\mathrm{BP}$ and $\mathrm{HR}$ variation in the two phases. There were no significant differences between the nifedipine phase and the benidipine phase in the office, 24-h, daytime, and nighttime BP or HR (Table 2). There were also no significant differences between the two phases in the morning BP and HR, or in the night lowest BP and HR, and there were no differences in BP or HR between daytime and nighttime or the diurnal BP variation of the baseline night-day ratios of BP and HR. Furthermore, there were no significant differences between the nifedipine phase and the benidipine phase in the 24-h, daytime and nighttime BP variation (SD of 24h, day and night BP) (Table 3). Figure 2 shows the mean $( \pm \mathrm{SE}) \mathrm{BP}$ and HR changes after administration (from 2 to $4 \mathrm{~h}$ ) of each drug in the morning. There were no signifi- cant differences in SBP, DBP, and HR levels before and after each drug. There were also no differences in the mean changes in BP and HR levels between the nifedipine and benidipine phases. As for evening administration of nifedipine, SBP and DBP after administration were lower than those before (before administration: SBP $137.6 \pm 2.9 \mathrm{mmHg}$, DBP $87.1 \pm 1.7 \mathrm{mmHg}$; after administration: SBP $118.6 \pm 2.7 \mathrm{mmHg}, \mathrm{DBP} 72.5 \pm 1.8 \mathrm{mmHg}$ : $p<0.01)$. However, these changes were also found in the same evening period during the benidipine phase.

\section{Diurnal Heart Rate Variability}

Figure 3 and Table 4 show the results of power spectral analysis of HRV during the two phases. There were no significant differences between nifedipine and benidipine for LF or HF and LF/HF ratios, 24-h, daytime and nighttime periods, the morning periods, the night-lowest periods, and the differences between daytime and nighttime. Figure 4 shows the changes in LF, HF, and LF/HF ratios after morning administration of each drug. There 
Table 2. Mean Blood Pressure Levels of Day and Night Periods in Nifedipine and Benidipine Phases

\begin{tabular}{|c|c|c|c|c|}
\hline & & Nifedipine & Benidipine & $p$ \\
\hline \multirow[t]{3}{*}{ Office } & SBP (mmHg) & $128.6 \pm 0.7$ & $130.8 \pm 0.7$ & NS \\
\hline & $\mathrm{DBP}(\mathrm{mmHg})$ & $79.9 \pm 0.4$ & $79.4 \pm 0.4$ & NS \\
\hline & HR (bpm) & $68.3 \pm 0.4$ & $69.0 \pm 0.4$ & NS \\
\hline \multirow[t]{3}{*}{ 24-h } & $\mathrm{SBP}(\mathrm{mmHg})$ & $128.3 \pm 0.6$ & $129.7 \pm 0.6$ & NS \\
\hline & $\mathrm{DBP}(\mathrm{mmHg})$ & $79.1 \pm 0.4$ & $78.7 \pm 0.4$ & NS \\
\hline & HR (bpm) & $67.9 \pm 0.4$ & $69.0 \pm 0.4$ & NS \\
\hline \multirow[t]{3}{*}{ Daytime } & $\mathrm{SBP}(\mathrm{mmHg})$ & $135.5 \pm 0.8$ & $136.7 \pm 0.8$ & NS \\
\hline & DBP $(\mathrm{mmHg})$ & $83.2 \pm 0.5$ & $82.6 \pm 0.5$ & NS \\
\hline & HR (bpm) & $72.2 \pm 0.5$ & $73.6 \pm 0.5$ & NS \\
\hline \multirow[t]{3}{*}{ Nighttime } & $\mathrm{SBP}(\mathrm{mmHg})$ & $115.8 \pm 0.8$ & $119.1 \pm 0.9$ & NS \\
\hline & DBP (mmHg) & $71.9 \pm 0.5$ & $73.1 \pm 0.6$ & NS \\
\hline & HR (bpm) & $60.5 \pm 0.5$ & $62.0 \pm 0.5$ & NS \\
\hline \multirow[t]{3}{*}{ Morning } & $\mathrm{SBP}(\mathrm{mmHg})$ & $136.4 \pm 5.2$ & $143.2 \pm 3.4$ & NS \\
\hline & DBP (mmHg) & $79.9 \pm 3.1$ & $85.5 \pm 2.6$ & NS \\
\hline & HR (bpm) & $74.5 \pm 2.2$ & $76.0 \pm 2.3$ & NS \\
\hline \multirow[t]{3}{*}{ Night-lowest } & $\mathrm{SBP}(\mathrm{mmHg})$ & $108.4 \pm 1.9$ & $110.1 \pm 2.0$ & NS \\
\hline & DBP $(\mathrm{mmHg})$ & $65.5 \pm 1.2$ & $66.6 \pm 1.6$ & NS \\
\hline & HR (bpm) & $57.0 \pm 0.9$ & $57.5 \pm 1.0$ & NS \\
\hline \multirow{6}{*}{$\begin{array}{l}\text { Difference between daytime } \\
\text { and nighttime } \\
\text { (\% change from day time period) }\end{array}$} & $\mathrm{SBP}(\mathrm{mmHg})$ & $28.7 \pm 4.2$ & $35.1 \pm 3.7$ & NS \\
\hline & $(\%)$ & $(-13.3 \pm 1.5)$ & $(-13.2 \pm 1.7)$ & \\
\hline & DBP $(\mathrm{mmHg})$ & $14.7 \pm 3.3$ & $19.3 \pm 3.3$ & NS \\
\hline & $(\%)$ & $(-13.2 \pm 1.6)$ & $(-12.4 \pm 1.8)$ & \\
\hline & HR (bpm) & $17.7 \pm 2.4$ & $18.5 \pm 1.9$ & NS \\
\hline & $(\%)$ & $(-15.3 \pm 1.8)$ & $(-16.4 \pm 2.0)$ & \\
\hline
\end{tabular}

Data are shown as the mean \pm SE. $P$ values are computed for the differences between nifedipine and benidipine administration measurement of blood pressure and heart rate (paired Student's $t$-test, NS: no significant difference (between two phases), SBP: systolic blood pressure, DBP: diastolic blood pressure.

Table 3. Variability of Blood Pressure and Heart Rate (Standard Deviations) during 24-h, Daytime, Nighttime Periods in Each Phase

\begin{tabular}{|c|c|c|c|c|}
\hline & & Nifedipine & Benidipine & $p$ \\
\hline \multirow[t]{3}{*}{ 24-h } & SBP & $17.4 \pm 4.9$ & $17.8 \pm 5.2$ & NS \\
\hline & DBP & $11.1 \pm 2.7$ & $11.5 \pm 2.7$ & NS \\
\hline & HR & $11.6 \pm 2.8$ & $11.9 \pm 3.3$ & NS \\
\hline \multirow[t]{3}{*}{ Daytime } & SBP & $16.2 \pm 4.6$ & $16.2 \pm 4.8$ & NS \\
\hline & DBP & $10.1 \pm 2.4$ & $10.6 \pm 2.5$ & NS \\
\hline & HR & $11.5 \pm 2.6$ & $11.7 \pm 3.8$ & NS \\
\hline \multirow[t]{3}{*}{ Nighttime } & SBP & $10.9 \pm 4.4$ & $11.6 \pm 3.7$ & NS \\
\hline & DBP & $7.3 \pm 2.1$ & $8.0 \pm 2.7$ & NS \\
\hline & HR & $5.4 \pm 1.8$ & $5.1 \pm 2.8$ & NS \\
\hline
\end{tabular}

Data are shown as the mean \pm SE. $P$ values are computed for the differences between nifedipine and benidipine administration measurement of blood pressure and heart rate (paired Student's $t$-test: NS, no significant difference between the two phases). SBP, systolic blood pressure; DBP, diastolic blood pressure.

were no significant differences between pre- and postadministration of each drug, except in the LF component of nifedipine. There were no differences in the mean change of each HRV parameter between nifedipine and benidipine (data not shown). As for administration of nifedipine in the evening, there were no significant differences in LF and HF components between before and after. The LF/HF ratio after administration was lower than that before (before administration: $\mathrm{LF} / \mathrm{HF}$ ratio $2.5 \pm 1.1$; after administration: LF/HF 1.7 $\pm 1.1: p<0.05$ ), howev- 

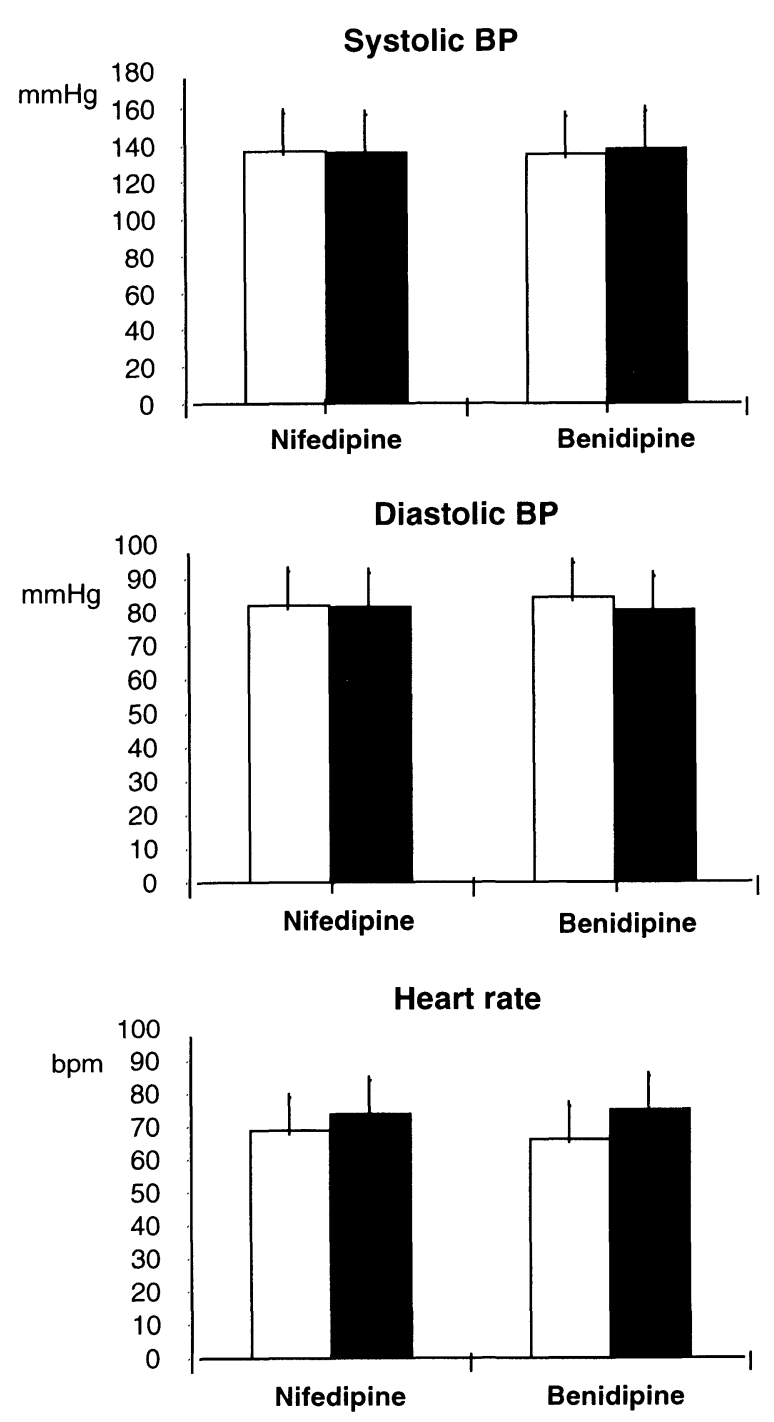

Fig. 2. Blood pressure (BP) and heart rate in two phases. Data are presented as mean $\pm S E$. ( $\square$ ) before administration of each drug. (四) from 2 or $4 \mathrm{~h}$ after administration of each drug.

er, there were no differences in the mean changes of the evening HRV parameters between nifedipine and benidipine (data not shown).

\section{Discussion}

In the present study, we demonstrated that administration of the intermediate-acting agent nifedipine and of the long-acting agent benidipine reduced the mean 24-h BP level to the same extent. Furthermore, we found that the nocturnal and morning BP reductions caused by twice daily administration of nifedipine was equivalent. There were also no significant differences between nifedipine and benidipine phases in BP variability (SD of 24-h, day and night BP) and diurnal sympatho-vagal balance assessed by HRV.

Bigger et al. (12) found that after myocardial infarction, patients had smaller LF and HF components compared to the control group. Hayano et al. (13) reported that coronary artery disease was associated with vagal dominant impairment in autonomic cardiac function and that reduction in vagal cardiac function correlates with angiographic severity. The HRV parameters were related neither to previous history of myocardial infarction nor to stenosis of any specific artery (data not shown).

We found no significant differences between the intermediate-acting calcium antagonist and the long-acting calcium antagonist in diurnal autonomic nervous activity when assessed by HRV.

A previous report (14) disclosed that the long-acting agent amlodipine did not induce an increase in sympathetic nerve activity assessed by HRV during ECG monitoring, and that of intermediate-acting (slow-releasing) nifedipine induced a milder reflex sympathetic activation than did short-acting nifedipine. There is another report showing that some calcium channel blockers have shorter ultradian periodicity of variation in SBP and DBP than other antihypertensive agents (15). Previously, we found that diurnal autonomic nervous system activity is related to diurnal BP variation (8). The reason for the lack of difference in HRV components between the two phases in our study might be due to a lack of significant difference in $\mathrm{BP}$ variability.

Rapid BP reduction induced by acute vasodilatation due to short-acting nifedipine elicits activation of the sympathetic nervous system and an adverse neurohormoral response. This sympathetic nervous system activation mechanism acts behind the observed proischemic, negative inotropic, and arrythmogenic effects (1). In this study, BP, HR, and HRV parameters (HF and LF/HF ratio) from 2 to $4 \mathrm{~h}$ after nifedipine administration (probably the most effective period of the intermediate agent) were not different from those before administration. There was a significant difference in the LF component. The LF power acts as an index of both sympathetic nervous and parasympathetic nervous activity (10). Since there was no significant difference in the LF/HF ratio, we could not conclude that the sympatho-vagal axis shifted to sympathetic activation after intermediate-acting nifedipine administration. In the administration of nifedipine in the evening, we found significant decreases in SBP, DBP and LF/HF. However, when compared with the same evening period of benidipine phase, the changes were not significantly different. Thus, these changes might be due not to the effect of the drug, but to behavioral changes in the evening (position, activity, etc). These behavioral factors are the determinants of daytime BP and diurnal BP variation (16).

A limitation of our study is that it is not a randomized 

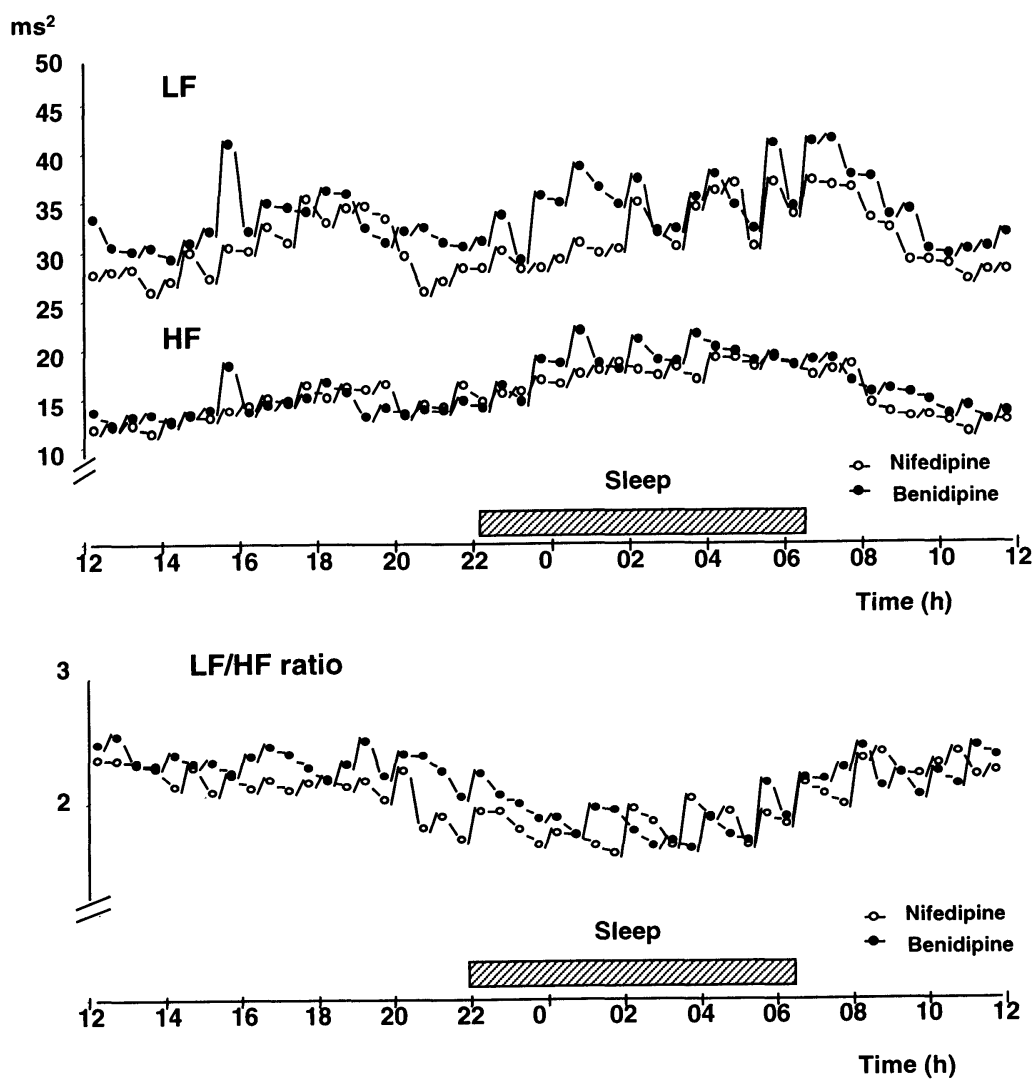

Fig. 3. Twenty-four-hour ambulatory recordings of mean low frequency power (LF), high frequency power (HF) and $L F / H F$ ratio between nifedipine and benidipine treatment in 25 hypertensive patients with coronary artery disease.

Table 4. Mean LF, HF, and LF/HF of Day and Night Periods in Nifedipine and Benidipine Phases

\begin{tabular}{|c|c|c|c|c|}
\hline & & Nifedipine & Benidipine & $p$ \\
\hline \multirow[t]{3}{*}{ 24-h } & $\mathrm{LF}\left(\mathrm{ms}^{2}\right)$ & $30.8 \pm 1.0$ & $33.8 \pm 1.0$ & NS \\
\hline & $\mathrm{HF}\left(\mathrm{ms}^{2}\right)$ & $15.3 \pm 1.0$ & $15.9 \pm 1.0$ & NS \\
\hline & $\mathrm{LF} / \mathrm{HF}$ & $2.0 \pm 1.0$ & $2.1 \pm 1.0$ & NS \\
\hline \multirow[t]{3}{*}{ Daytime } & $\mathrm{LF}\left(\mathrm{ms}^{2}\right)$ & $29.8 \pm 1.0$ & $32.8 \pm 1.0$ & NS \\
\hline & $\mathrm{HF}\left(\mathrm{ms}^{2}\right)$ & $13.7 \pm 1.0$ & $14.3 \pm 1.0$ & NS \\
\hline & $\mathrm{LF} / \mathrm{HF}$ & $2.2 \pm 1.0$ & $2.3 \pm 1.0$ & NS \\
\hline \multirow[t]{3}{*}{ Nighttime } & $\mathrm{LF}\left(\mathrm{ms}^{2}\right)$ & $32.7 \pm 1.0$ & $34.6 \pm 1.0$ & NS \\
\hline & $\mathrm{HF}\left(\mathrm{ms}^{2}\right)$ & $18.2 \pm 1.0$ & $18.1 \pm 1.0$ & NS \\
\hline & $\mathrm{LF} / \mathrm{HF}$ & $1.8 \pm 1.0$ & $1.9 \pm 1.0$ & NS \\
\hline \multirow[t]{3}{*}{ Morning } & $\mathrm{LF}\left(\mathrm{ms}^{2}\right)$ & $30.6 \pm 1.1$ & $36.9 \pm 1.0$ & NS \\
\hline & $\mathrm{HF}\left(\mathrm{ms}^{2}\right)$ & $14.7 \pm 1.1$ & $16.5 \pm 1.1$ & NS \\
\hline & $\mathrm{LF} / \mathrm{HF}$ & $2.1 \pm 1.0$ & $2.2 \pm 1.0$ & NS \\
\hline \multirow[t]{3}{*}{ Night-lowest } & $\mathrm{LF}\left(\mathrm{ms}^{2}\right)$ & $29.1 \pm 1.1$ & $35.4 \pm 1.1$ & NS \\
\hline & $\mathrm{HF}\left(\mathrm{ms}^{2}\right)$ & $17.4 \pm 1.1$ & $11.4 \pm 1.2$ & NS \\
\hline & $\mathrm{LF} / \mathrm{HF}$ & $1.8 \pm 1.1$ & $1.9 \pm 1.2$ & NS \\
\hline \multirow{3}{*}{$\begin{array}{l}\text { Difference between daytime } \\
\text { and nighttime }\end{array}$} & $\mathrm{LF}\left(\mathrm{ms}^{2}\right)$ & $1.1 \pm 0.4$ & $1.2 \pm 0.2$ & NS \\
\hline & $\mathrm{HF}\left(\mathrm{ms}^{2}\right)$ & $0.9 \pm 0.5$ & $1.1 \pm 0.1$ & NS \\
\hline & $\mathrm{LF} / \mathrm{HF}$ & $1.3 \pm 0.8$ & $1.4 \pm 0.2$ & NS \\
\hline
\end{tabular}

Data are shown as the mean \pm SE. $P$ values are computed for the differences between nifedipine and benidipine administration measurement of HRV components (paired Student's $t$-test, NS, no significant difference among the three periods); LF, low frequency $(0.04-0.15 \mathrm{~Hz})$ component of the power spectrum; HF, high frequency $(0.15-0.4 \mathrm{~Hz})$ component of the power spectrum. 

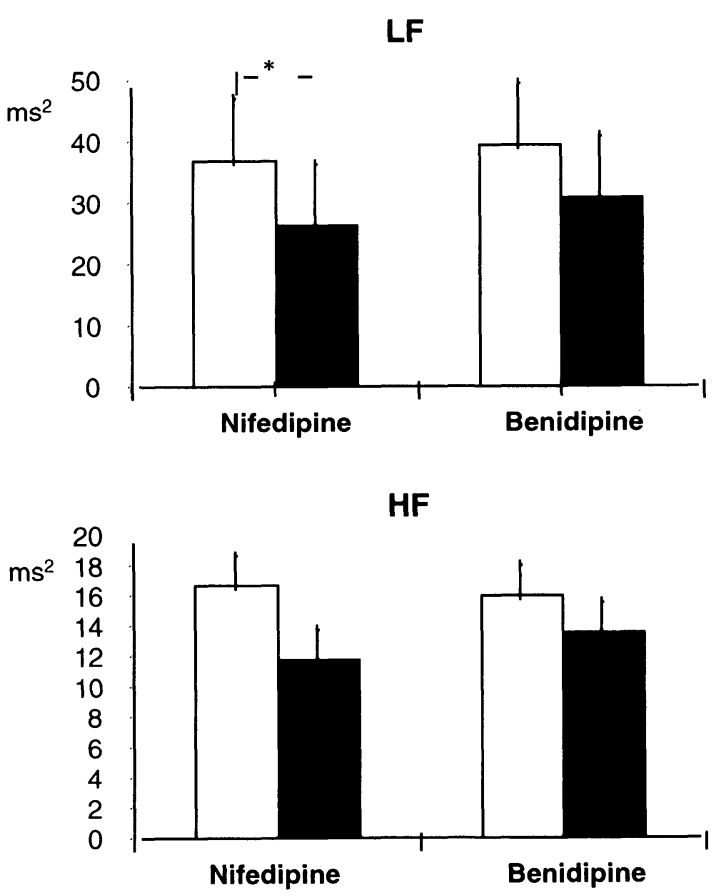

LF/HF RATIO

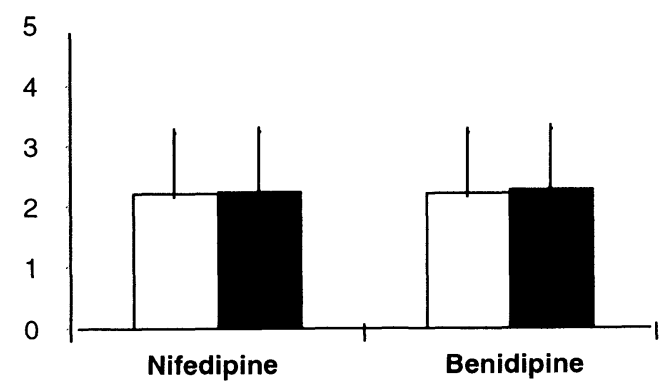

Fig. 4. Low frequency (LF), high frequency $(H F)$ and $L F / H F$ ratio in two phases. Data are presented as means \pm SE. ( $\square$ ) before administration of each drug. ( $\square$ ) from 2 or $4 h$ after administration of each drug. ${ }^{*} \mathrm{p}<0.05$.

crossover study. The patients studied had been treated by intermediate-acting nifedipine agent for at least 3 mo and during the study period. Therefore, there is a possibility that only patients who tolerated nifedipine well were selected. These patients may be resistant to sympathetic activation by calcium antagonists. Also, daily sympathetic activation after nifedipine administration may be suppressed by long-term use of nifedipine. These factors may have masked the difference in the sympatho-vagal balance between nifedipine and benidipine in the patients we studied.

In conclusion, when hypertensive patients with coronary artery disease whose BP levels were well-controlled by twice daily use of intermediate-acting nifedipine switched from nifedipine to a long-acting calcium antagonist, benidipine, well-controlled BP levels were maintained to a similar degree, but the drug may not have the additional benefit in sympatho-vagal balance.

\section{References}

1. Furberg CD, Pasty BM, Meyer JV: Nifedipine: Dose-related increase in mortality in patients with coronary heart disease. Circulation 1995; 92: 1326-1331.

2. Ad Hoc Subcommittee of the Liaison Committee of the World Health Organisation and the International Society of Hypertension: Effects of calcium antagonists on the risks of coronary heart disease, cancer and bleeding. Hypertens Res 1997; 20: 61-73.

3. Joint National Committee on Detection, Evaluation, and Treatment of High Blood Pressure: The sixth report of the Joint National Committee on Prevention, Detection, Evaluation, and Treatment of High Blood pressure. Arch Intern Med 1997; 157: 2413-2446.

4. Ruzicka M, Leenen FHH: Relevance of intermittent increase in sympathetic activity for adverse outcome on short-acting calcium antagonists, in: Laragh JH, Brenner BM (eds): Hypertension; Pathophisiology, Diagnosis, and Management. New York, Raven Press, 1995, pp28152825.

5. Alderman $\mathrm{MH}$, Cohen $\mathrm{H}$, Roqu R, Madhaven S: Effect of long-acting calcium antagonists on cardiovascular outcomes in hypertensive patients. Lancet 1997; 349: 594598.

6. Meredith PA, Elliott HL: FDA guidelines on trough: peak ratios in the evaluation of antihypertensive agents. J Cardiovasc Pharmacol 1994; 23 (Suppl): S26-S30.

7. Kohara K, Nishida W, Maguchi M, Hiwada K: Autonomic nervous function in non-dipper essential hypertensive subjects: evaluation by power spectral analysis of heart rate variability. Hypertension 1995; 26: 808-814.

8. Kario K, Motai K, Mitsuhashi T, et al: Autonomic nervous system dysfunction in elderly hypertensive patients with abnormal diurnal blood pressure variation: relation to silent cerebrovascular disease. Hypertension 1997; 30: 1504-1510.

9. Tochikubo O, Ikeda A, Miyazima E, Ishii M: Effects of insufficient sleep on blood pressure monitored by a new multibiomedical recorder. Hypertension 1996; 27: 13181324.

10. Berger RD, Akelrod S, Gordon D, Cohen RJ: An efficient algorithm for spectral analysis of heart rate variability. IEEE Trans Biomed Eng 1981; 33: 900-904.

11. Task Force of the European Society of Cardiology and North American Society of Pacing and Electrocardiology. Heart rate variability: standards of measurement, physiological interpretation, and clinical use. Circulation 1996; 93: 1043-1065.

12. Bigger JT Jr, Fleiss JL, Rolinitzky LM, Steinman RC, 
Schneider WJ: Time course of recovery of heart period variability after myocardial infarction. J Am Coll Cardiol 1991; 18: 1643-1649.

13. Hayano J, Sakakibara Y, Yamada M, et al: Decreased magnitude of heart rate spectral components in coronary artery disease. Circulation 1990; 81: 1217-1224.

14. Hamada $T$, Watanabe M, Kaneda $T$, et al: Evaluation of changes in sympathetic nerve activity and heart rate in essential hypertensive patients induced by amlodipine and nifedipine. J Hypertens 1998; 16: 111-118.

15. Kawamura H, Mitsubayashi H, Saito $\mathrm{T}$, et al: Calcium channel blockers shorten the periodicity of ultradian variation in blood pressure in patients with essential hypertension. Hypertens Res 1998; 21: 179-186.

16. Kario K, Schwartz JE, Pickering TG: Ambulatory physical activity as a determinant of diurnal blood pressure variation. Hypertension 1999; 34: 685-691. 